\title{
Origin, State of the Art and Some Prospects of the Diamond CVD
}

\author{
Boris V. Spitsyn, Leonid L. Bouilov, Alexander E. Alexenko \\ Institute of Physical Chemistry, Russian Academy of Sciences, \\ 31 Leninsky Prospekt, 117915 Moscow, Russia
}

Received 6 May, 2000

\begin{abstract}
A short review on the diamond CVD origin, together with its state of the art and some prospects was given. New hybrid methods of the diamond CVD permit to gain 1.2 to 6 times of growth rate in comparison with ordinary diamond CVD's. Recent results on n-type diamond film synthesis through phosphorus doping in the course of the CVD process are briefly discussed. In comparison with highpressure diamond synthesis, the CVD processes open new facets of the diamond as ultimate crystal for science and technology evolution. It was stressed that, mainly on the basis of new CVDs of diamond, the properties of natural diamond are not only reproduced, but can be surpassed. As examples, mechanical (fracture resistance), physical (thermal conductivity), and chemical (oxidation stability) properties are mentioned. Some present issues in the field are considered.
\end{abstract}

\section{Introduction}

Diamonds for long time attracted special attention of men due to unsurpassed hardness and noble appearance produced by reflected and refracted light beams. Now it is widely known that the diamond, being one of the crystalline phases of pure carbon, has an exclusive combination of mechanical, physical and chemical properties. From the list we shall note, extremely low compressibility, enormous thermal conductivity, excellent radiative resistance, and also high chemical inertness. Together with many other individual properties and, in particular, on their totality [1] diamond far surpasses any known material. Therefore it occupies the highest level in their hierarchy, and can be termed as a unique supermaterial.

The plurality of exclusive properties of diamond is caused, on the one hand, by the presence in its structure of short and strong covalent chemical bonds between carbon atoms, with considerable radial and angular rigidity. It is indeed the original reason of extreme mechanical and physical characteristics and chemical stability of diamond. On the other hand, the rather low nuclear charge of carbon atom, together with the above mentioned bonds strongness, causes high radiative resistance of diamond, by 2-3 orders of magnitude exceeding the radiative resistance of silicon.

However, the wide use of specific properties of diamond, and their combinations in scientific and industrial practice were restricted both by limitations of natural resources of diamond and specificity of traditional methods of its synthesis. At present, there are four diamond sources:

- natural deposits.

- synthesis at static high pressure and temperature.

- synthesis at dynamic high pressure and temperature (explosive and detonation methods). In explosive process designed by DuPont (1970), the duration of the explosion, creating high pressure and temperature, was $\sim 1 \mathrm{~ms}$, and size of crystal grains of diamond amounts 1-50 $\mu \mathrm{m}$. In detonation process discovered in the eighties by the Russian researchers, the duration and size are equal to $\sim 0.3 \mu \mathrm{s} \sim 4 \mathrm{~nm}$, respectively.

- synthesis from a gas phase in the conditions of thermodynamic metastability of diamond at low pressures.

This review will be devoted to the last method of synthesis, which after a pioneering publication [2], has been studied and developed worldwide during the last eighteen years.

\section{From the analysis to the synthesis}

The synthesis of diamond became possible only after the establishment of its chemical composition and determination of a crystalline structure. It is remarkable, however, that even before of the qualitative analysis of diamond carried out by A.Lavoisier (France) and its quantitative analysis performed by S.Tennant (England), the Russian scientist M.V. Lomonosov in 1762 has offered the regrowth of diamond seed crystals from media, in which he guessed to crystallize some other 
minerals. Though to Lomonosov did not know neither the chemical composition of diamond nor its crystalline structure, his idea has appeared as prophetical.

For the modern chemistries, physicochemistries and physicists, highly suggestive in the search of alternative inroads to the diamond synthesis was the chemical constitution of the diamond. The structure of latter represents huge molecule constructed from atoms of carbon, connected with each other by covalent $s p^{3}$-bonds. Though this structural state is not thermodynamically stable, there were not some prohibitions for trials of its chemical synthesis. In organic chemistry, for example, synthesis of not absolutely stable molecules is rather a rule, than an exception. The diamond, being metastable under usual conditions in relation to graphite, conserve its own structure at pressure close and below $1 \mathrm{~atm}$ and temperature up to and more than $1000^{\circ} \mathrm{C}$, depending on the nature of surrounding gas medium. In ultra-high vacuum or in an atmosphere of ultra-pure hydrogen the diamond retain the structure of surface layer identical to the bulk up to temperatures in the range of $1300-1400{ }^{\circ} \mathrm{C}$ [3]. Therefore could arise the idea to take advantage of this relative stability of diamond for its synthesis at the expenses of new carbon atoms. It was supposed that, under the action of directional activity of surface forces, the bonds between the atoms at the diamond surface and carbon atoms from decomposing carbonaceous substances will rebuild diamond, if exclusively $s p^{3}$-bonding formation was provided. Thus, it was required to find conditions at which mainly and with high enough rate only $s p^{3}$ type carbon-carbon bonds are formed and the formation of other types of bonding between carbon atoms at the surface of growing diamond are completely excluded. Such methods of chemical synthesis or chemical vapor deposition (CVD) of diamond were proposed almost simultaneously in Russia (USSR) and in USA in the second half of the fifties of now expired last century. As molecules-carriers of carbon atoms it was offered methane and its least stable derivative, like tetrabromomethane and tetraiodomethane, simple organic methyl- contained molecules and carbon monoxide [46 . The typical decomposition temperature was equal to $900-1100{ }^{\circ} \mathrm{C}$ and the pressure ranged from parts of Torr up to $100 \mathrm{~atm}$.

Processes [4-6] demonstrate, for the first time, the opportunity to grow an artificial diamond by nearly isothermal pyrolisis of simple carbon-contained substances. However, the mentioned above chemical inertness of diamond did not promote well enough effectivity. The first processes [4-6] were characterized by low growth rate of new diamond, $\sim 1 \mathrm{~nm} / \mathrm{h}$, and did not have selectivity; together with diamond deposition, centers of graphite and other nondiamond states of carbon arose, and through their propagation diamond regrowth ceased and finally stopped. Besides, the originally offered processes [4-6] required as substrates the diamond seed crystals or highly disperse diamond powders. In the first open publication on the diamond CVD, the deposition of nondiamond carbon was declared as inevitable [7], though, at that time, the results about deposition of submicrometer and micrometer thick diamond films (DF) without co- deposition of non desirable graphite (see Section IV) in a mode of chemical transport [8-10], and also with the gas - transporting set-up $[11,12]$ were not published yet.

As the body of the publication is the synthesis of diamond as metastable phase of carbon, it is reasonable to consider the energetic of the basic species of carbon.

\section{Energetic of the basic carbon species}

Energetic of a series of solid carbon states (diamond, carbines, graphite, monoplane of graphite - graphene, amorphous tetrahedral carbon, fullerene C-60 and single-wall carbon nanotubes of a minimum diameter) and gaseous carbon (atom in the ground and first excited state) in simplified consideration, i.e. taking into account only standard enthalpy of formation (pressure - $1 \mathrm{~atm}$, temperature $-298^{\circ} \mathrm{C}$ ), is presented in Fig. 1 .

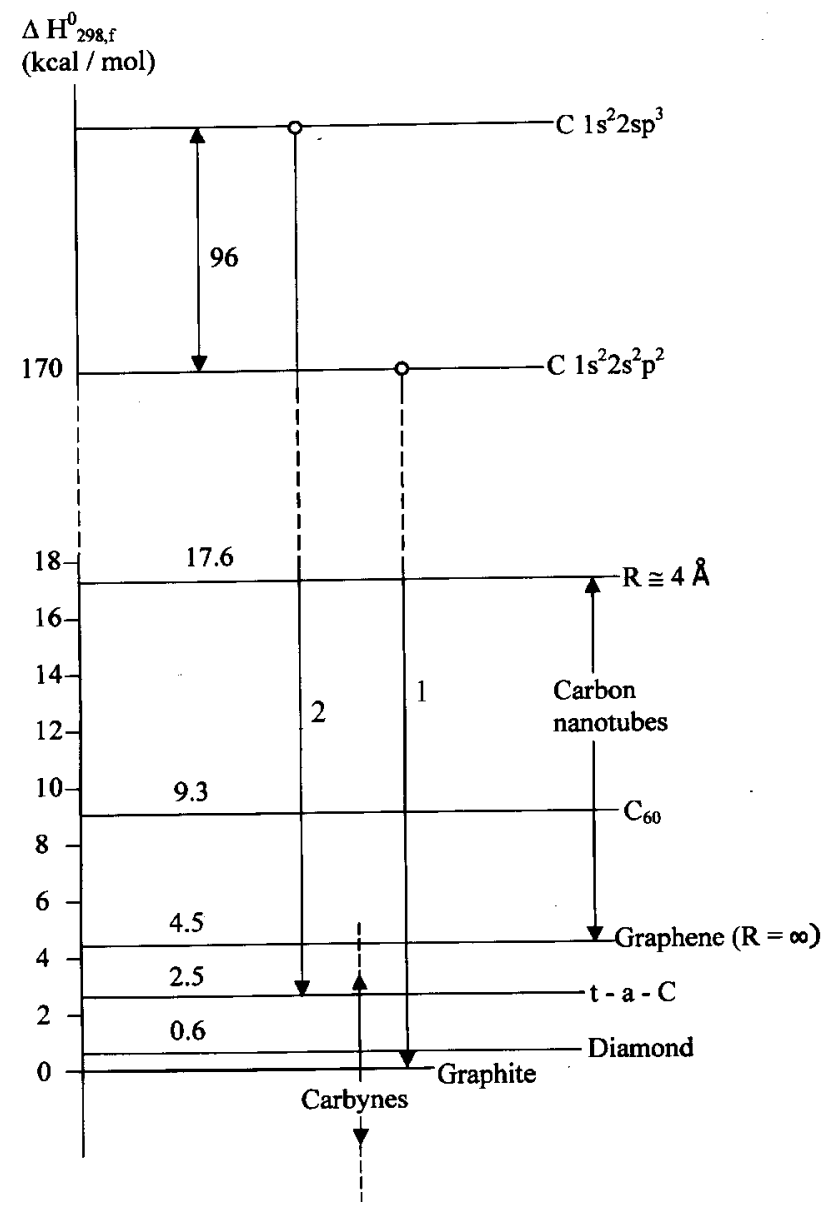

Figure 1. Standard enthalpies of pure carbon states. 
The analysis of Fig. 1 allows one to make the following basic conclusions. First, the enthalpy difference of diamond and graphite is rather low, in comparison the values for C-60 and carbon nanotubes. Secondly, the physical condensation of carbon atom from its ground electronic state, in which it is divalent, most likely lead to formation of non diamond-like phase, but graphitelike carbon phase (as points arrow 1). On the other hand, in the case of carbon atom being in electronically excited (tetravalent) state, their condensation in a solid carbon film with mainly tetrahedral coordination of atoms will be preferably formed, with the formation of the so- called tetrahedral or diamond-like amorphous carbon (arrow 2 in Fig. 1). It is possible to get diamond carbon with tetrahedral coordination of atoms not only in first, but also in second and in the subsequent coordination spheres. One of the mandatory conditions for such perfect volumetric crystallization should be rather low supersaturation of the process. But initial processes of the CVD suffer of extremely low growth rates even at high supersaturation.

\section{Search of systems for rapid crystallization of diamond from vapor}

Nevertheless, one of the authors (B. V. S.) decide to concentrate attention on overcoming at least of one of the above-stated drawbacks of the primary diamond CVD's - extremely low linear growth rate, amounted only $\sim 1 \mathrm{~nm} / \mathrm{h}$. It was reasonable to expect quick diamond growth in systems in which it is possible to implement a prompt etching of diamond. Apparently, the growth rate should be of the same order or below the value of the etching rate. In the sixties, it was not known of prompt processes of etching diamond in gaseous media, except for inflammability of diamond in pure oxygen, which begins at $850{ }^{\circ} \mathrm{C}$. However, this process completely shifted to oxidizing products - CO and $\mathrm{CO}_{2}$, and cannot be made reversible.

In the beginning of 1965 the Gulbransen's and coauthors paper [13], has appeared. It was shown by the authors that the etching of graphite in pure hydrogen at pressure of some Torr at temperature $1650{ }^{\circ} \mathrm{C}$ proceeds with rate of $2.4 \mathrm{~mm} /$ day.

At that point arose an idea on use of yields of hightemperature interaction of graphite with hydrogen as crystallizing medium for diamond upscaling. The seed crystal of diamond with temperature about $1000{ }^{\circ} \mathrm{C}$, was placed near graphite heated up to $2000{ }^{\circ} \mathrm{C}$, at hydrogen pressure of 12 Torr. Onto the seed crystal of diamond, a deposit of white condensed carbon is found, that has allowed to state that a transport of carbon from graphite on diamond with participation of atomic hydrogen took place [8]. The study was prolonged by
B.V. Spitsyn and A.V. Lavrent'ev. As far back as October, 1966 they demonstrate for the first time the epitaxial DF regrowth on natural (111) face with rate of $\sim 1 \mu \mathrm{m} / \mathrm{h}$. The set-up of the experiment is shown in Fig. 2. Remarkably, that at long-termed experiments the DF thickness could be about $10 \mu \mathrm{m}$ and more, without formation of any traces of graphite in the composition of the film. Such absence of the graphite co-deposition allowed for the first time to study kinetics of crystallization, for example, dependence of DF growth rate vs. temperature [11]. The basic mechanism of the chemical transport was established:

$$
\begin{gathered}
\text { Graphite }\left(\sim 2000^{\circ} \mathrm{C}\right)+\left(\mathrm{H}_{2}, \mathrm{H}\right) \rightarrow \mathrm{C}_{2} \mathrm{H}_{2} \rightarrow \\
\text { diamond }\left(\sim 1000^{\circ} \mathrm{C}\right)+\mathrm{H}_{2} .
\end{gathered}
$$

At prolonged carrying out the process (1), etching of the graphite holder (Fig. 2) of diamond seed crystal was observed. Quantitatively to explore this phenomenon, on a place of seed crystal of diamond (Fig. 2), a plate of isotropic carbon with density of $2.06 \mathrm{~g} / \mathrm{cm}^{3}$ was placed. In rather wide temperature range - from $800{ }^{\circ} \mathrm{C}$ up to $1300{ }^{\circ} \mathrm{C}$ graphite was subjected to etching in the same conditions, in what DF growth occurred. The etching rate of the graphite plate rise with temperature lowering and became equal to $6 \mu \mathrm{m} / \mathrm{h}$ at $800{ }^{\circ} \mathrm{C}$ [14]. In the Fig. 3, the kinetics of $\mathrm{DF}$ growth and graphite interaction with a gaseous phase with a nearly identical composition at 60 Torr is plotted. One can see that there is a rather wide range in which the diamond growth is possible and graphite growth (and, obviously, it self-nucleation) is impossible. It is enlightening that the 'solubility' (at total pressure $=76$ Torr) of carbon in the gas phase, $[\mathrm{C}] /[\mathrm{C}]+[\mathrm{H}]$, presented in the Fig. 3, passes through a minimum, which position, however, is far from the maximum of the growth rate of a diamond film.

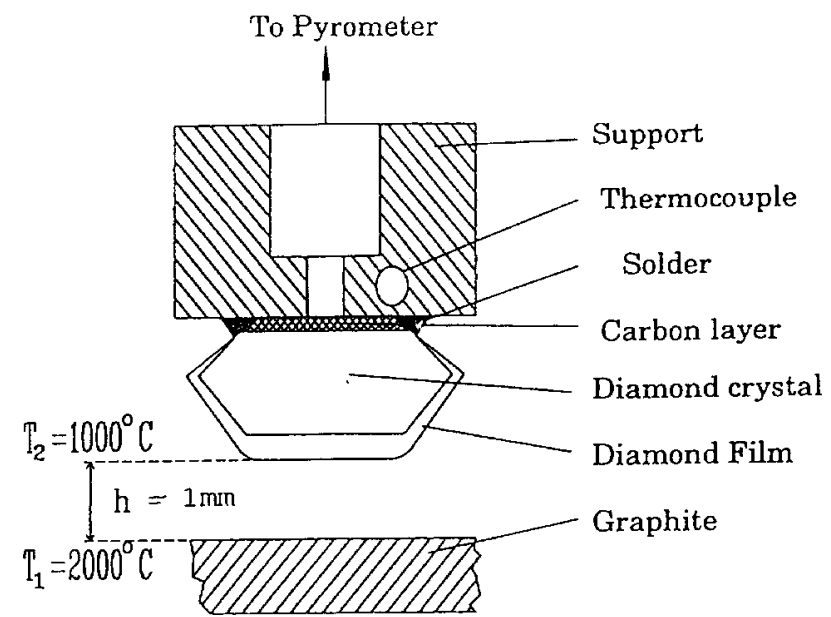

Figure 2. General set-up of HGCTR. After equilibration at $\mathrm{T}_{1}$ in $\mathrm{H}_{2}$ at 12 Torr, $\mathrm{C}_{2} \mathrm{H}_{2}, \mathrm{H}$ and $\mathrm{H}_{2}$ are transported by diffusion to the diamond seed surface and at $\mathrm{T}_{2}$ grow epitaxial diamond film. 


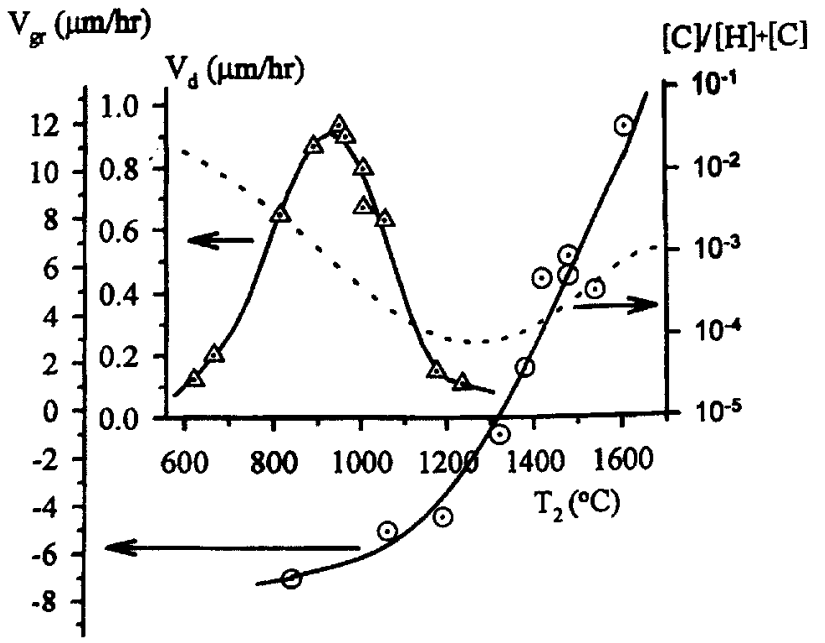

Figure 3. DF growth rate, $V_{d}$ (triangles), and graphite interaction rate, $V_{\mathrm{gr}}$ (circles), vs. substrate temperature, $\mathrm{T}_{2}$, under nearly identical conditions of the chemical transport reaction $\left(\mathrm{T}_{1}=2000^{\circ} \mathrm{C}, \mathrm{h}=1 \mathrm{~mm}, \mathrm{P}_{\text {tot }}=60\right.$ Tor $)$. Dotted line presents $\mathrm{C} / \mathrm{C}+\mathrm{H}$ ratio in the vapor phase at it total pressure, $\mathrm{P}_{\text {tot }}=76$ Tor.

During less than two decades the activated CVD was widely disseminated, improved and are explored in hundreds of laboratories of all technically advanced countries of the world. In the base of modern activated CVD of diamond $[15,16]$, there are four basic methods of gas phase activation:

- thermal,

- electrical (DC, RF and $\mathrm{mW}$ discharges),

- chemical

- photochemical.

The plurality of the CVD's and activated CVD's is demonstrated in Fig. 4.

Among the activated CVD methods, the most disseminated are

\section{Plasma chemical methods of diamond synthesis}

For plasma-chemical diamond synthesis (PDS) nearly any of the known low temperature plasma reactors can be used. The gas phase contains initially hydrocarbons in mixture with hydrogen, and also various combinations of intermixtures $\mathrm{CO}, \mathrm{CO}_{2}, \mathrm{H}_{2} \mathrm{O}, \mathrm{H}_{2}$, simple organic compounds (alcohols, etc.), and halogenohydrocarbons. It was exposed to a heating and simultaneously conversion in various kinds of electric discharge. A final product PDS is, depending on plasma conditions and substrate nature, single crystal or polycrystalline DF. However contrarily to precipitation of so named diamond-like carbon, at PDS a pure diamond, with the content of carbon atoms in $s p^{3}$ electronic state, close to $100 \%$ was achieved. As a result, the microscopic and macroscopic properties of synthesized diamond (hardness, thermal conductivity, etc.) are nearly identical of the properties of natural diamond. High selectivity (no co-deposition of any kind of solid carbon, except of diamond) of the PDS is caused by a considerable concentration of free radicals: $\mathrm{H}, \mathrm{O}, \mathrm{OH}$, etc. in the plasma volume. Their presence provides a preferred etching of any nondiamond carbons. Atomic hydrogen become not only a key substance for smooth its own diamond surface regrowth, but in the spontaneous self-nucleation of diamond on nondiamond substrates (metals, oxides, carbides, nitrides etc.).

As a starting gaseous mixture $(0.5-5) \% \mathrm{CH}_{4}$ in $\mathrm{H}_{2}$ will usually be utilized, at pressure in the range of tens and hundreds Torr. After starting in the mixture of an electric discharge, the conversion of stable molecules $\mathrm{CH}_{4}$ into neutral and charged hydrocarbonaceous particles: $\mathrm{C}_{2} \mathrm{H}_{2}, \mathrm{C}_{2} \mathrm{H}_{4}, \mathrm{CH}_{3}, \mathrm{C}_{2} \mathrm{H}, \mathrm{CH}_{2}, \mathrm{C}_{2}, \mathrm{CH}^{+}, \mathrm{CH}_{2}^{+}$, etc. proceeds. The considerable fraction (from several $\%$ up to $90 \%$ ) of $\mathrm{H}_{2}$ molecules dissociates to $\mathrm{H}$ atoms, and also to ions $\mathrm{H}^{+}, \mathrm{H}_{3}^{+}, \mathrm{H}^{-}$. The plasma ionization degree in the majority of the plasma reactors is $\sim 10^{-7}$. The DF crystallization temperature usually is 700 to $900{ }^{\circ} \mathrm{C}$, and the average temperature of the activated gas phase is much higher (from 2000 up to $5000{ }^{\circ} \mathrm{C}$ ). Crystallizing medium at PDS is, as a rule, classified as low temperature nonequilibrium plasma. Most widely for PDS the following kinds of discharges are applied: a direct current and its updating (arc-jet), RF (preferably, induction), microwave, and ECR.

In comparison with a glow discharge, the dc-electric arc (DCEA) has three essential peculiarities: high pressure of a gaseous discharge, usually tens and hundreds Torr, considerably smaller gap between electrons and heavy particles temperature (nearly isothermal plasma), and high concentrations of atomic hydrogen and hydrocarbon particles ensuring considerable growth rates of diamond.

DCEA belongs to stationary self-sustained discharges operating at voltage from $\sim 50$ to several hundreds Volts. The most typical pressure of gas - up to hundreds of Torr, and current density on the anode up to several A.cm ${ }^{-2}$. The cathode is made of highmelting metals or their carbides (W, Ta). The anode usually served as the holder of substrates for DF deposition. In the latter case, because of the high dielectric properties of diamond down to $1000{ }^{\circ} \mathrm{C}$, problems with homogeneity of discharge near to the surface of growing DF occurs. They can be solved by various methods, in particular, by arrangement of a substrate for DF regrowth immediately behind the perforated anode [17].

Reactors for DCEA can operate with 'hot' $[18,19]$ and 'warm' [20] cathode, with cathode to anode ratio of the areas of $<<1$ and $>1$, respectively. Tungsten or tantalum carbides are the most appropriate materials for 'hot' cathode. Typical cathode temperature does not exceeds $2500{ }^{\circ} \mathrm{C}$ and can not be essentially boosted without hazard of quick sputtering of the cathode material and metal impurity invasion to growing DF. 


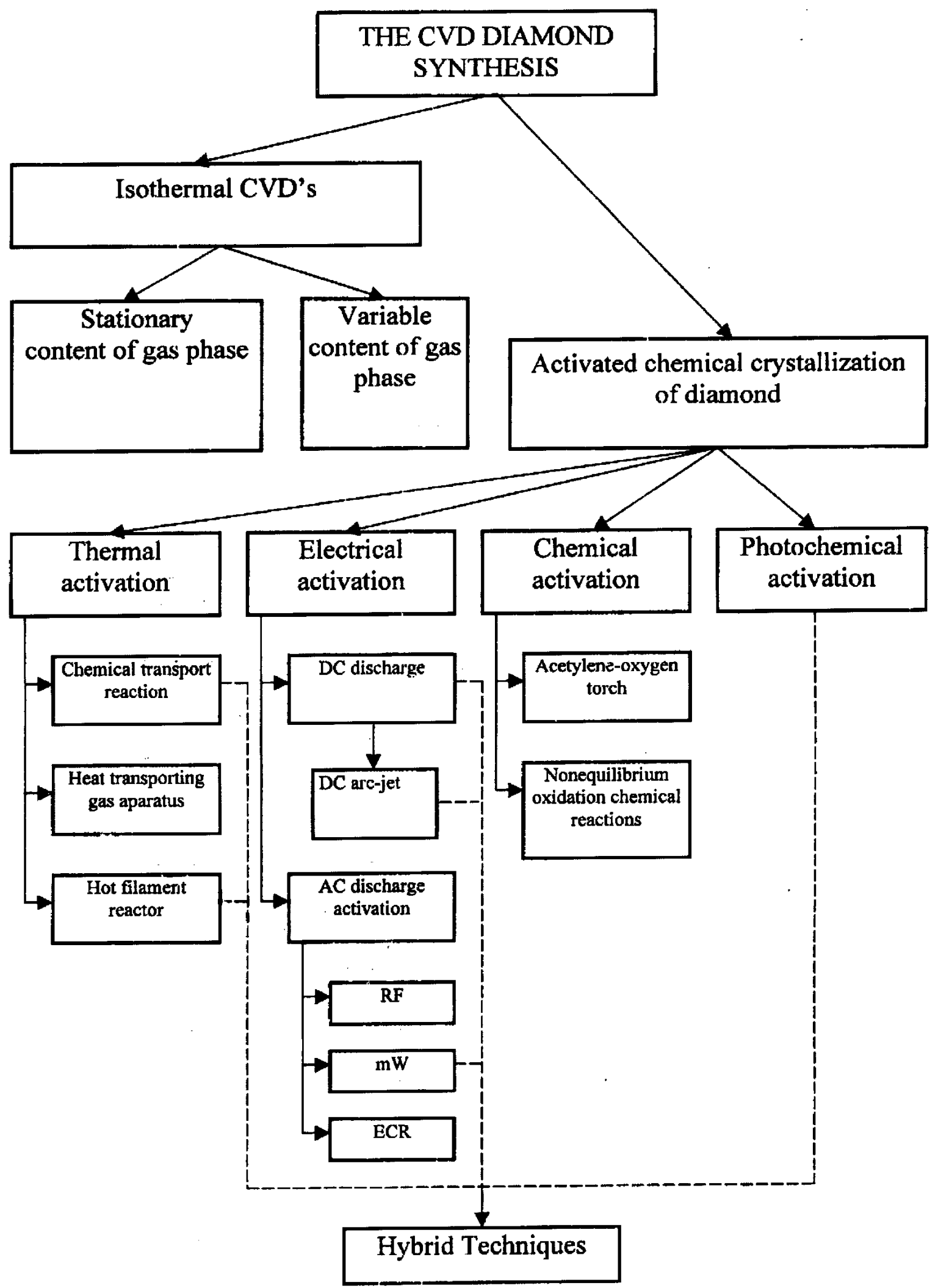

Figure 4. Diamond CVD ies. 
Molybdenum usually serves as the warm cathode (800-1200 $\left.{ }^{\circ} \mathrm{C}\right)$. The stability of discharge at DCEA provided with a ballast resistor, or by active electronic controller. The secondary ion-electronic emission may contain appreciable fraction of electrons escaping from 'hot' cathode. Also the emission should be dominating in the case of the 'warm' cathode. It results that 'hot' cathode DCEA provides (in comparison with 'warm' cathode DCEA) DF with higher quality, on the area of $\sim 1 \mathrm{~cm}^{2}$. Also are known multi- cathode systems (with several parallel hot cathodes) allowing producing the DF on the area of some centimeters square.

The simplicity and relative cheapness of design and operation is characteristic for DCEA. The yield of diamond in relation to carbon-contained gas flow may amount up to $30 \%$.

Some difficulties described above with the DCEA, may be cancelled in direct current plasmatron (DCP) [21].

In DCP, the low-voltage electrical arc is ignited between coaxially located thoriated tungsten cathode and water-cooled copper anode. As plasma-forming gas, the mixture of Ar with $\sim 20 \% \mathrm{H}_{2}$, and carbon-contained gas (methane) is served. The flow velocity is in the range of $1-10 \mathrm{~km} / \mathrm{s}$ [22]. Remoted from discharge gap plasma torch directed to water-cooled substrate, e.g. molybdenum. The average temperature of plasma near to a growing DF surface is $900-1900{ }^{\circ} \mathrm{C}$. High linear growth rate of DF in DCP (up to $1 \mathrm{~mm} / \mathrm{h}$ and $0.2 \mathrm{~mm} / \mathrm{h}$, for polycrystalline and single crystal DF, respectively) and considerable transformation of carbon of a gas phase into synthetic diamond (up to $8 \%$ ) make DCP suitable for the CVD diamond production in commercial scale.

In the PDS, the two RF-discharge modes can be utilized: capacitive (RFC) and inductive (RFI) one. The first positive results on PDS were achieved in RFC discharge raised with use of frequencies from $100 \mathrm{~Hz}$ to 10 $\mathrm{MHz}$ in hydrocarbon - hydrogen gas phases at pressure 0.08-15 Torr [23]. Various RFC versions including superimposition on plasma of an exterior magnetic field are tested for covering by DF large surface area. Obtained submicrocrystalline DF, as a rule, contains some nondiamond carbon phases. However, like was recently demonstrated [24], RFC provides nanosize grained DF with $97 \%$ of diamond phase content, highly compatible with medicine aimed bone prosthesis.

RFI discharges being electrodeless, allows, basically, avoiding pollution by electrode impurities in both plasma and growing DF. The impurity supply from the walls of a reactive vessel can be reduced by their flushing by the gas flow that has been not involved in RFdischarge [25]. The achieved growth rate of polycrystalline DF in the $40 \mathrm{~kW}$ RFI-discharge is $30 \mu \mathrm{m} / \mathrm{h}$. At a substrate diameter of $100 \mathrm{~mm}$ diamond CVD goes with productivity up to 5 carat/h [26].

The microwave discharge is also electrodeless and can be carried out in a reactor with quartz [27] or cooled metal wall [28]. On the basis of discharges with frequency of 2.45 and $0.915 \mathrm{GHz}$, an industrial production of PDS reactors with working area up to $100 \mathrm{~mm}$ diameter and more can be organized. However, capital rates on production of the reactors and working costs (replacement of magnetrons, etc.) are high. Therefore, for some of the practical purposes the PDS in reactors with DCEA and DCP can be preferable.

The plasma gained in a mode of an electronic cyclotron resonance (ECR) [29], essentially differs from all before surveyed. The motion of the accelerated electrons in a magnetic field with a resonant frequency allows pressure of gas $\left(\mathrm{H}_{2}\right.$ plus $\left.\mathrm{CH}_{4}\right)$ of fraction of Torr to achieve ionization degree close to $100 \%$. Accordingly, energy of heavy particles can reach some eV. It allows to receive $\mathrm{DF}$ well adhering to surface of metals and dielectrics even at temperature down to $200-300{ }^{\circ} \mathrm{C}$.

Only restricted number of publications reporting the use of laser plasma [30] show, that, despite of apparent expensiveness of this method, it can give unique opportunities at PDS, for example by the deposition of ultra-thin DF on a surface of polymers.

In plasma enhanced CVD's more than one activation action towards to gas phase and growing DF surface have been existed. Together with electrical and thermal activation the $\mathrm{UV}$ radiations action typically take place.

\section{Hybrid methods of the diamond CVD}

It is interesting to know more about intentional applying co-action of different activation modes to the diamond CVD's in so named hybrid diamond CVD methods [31].

The CVD efficiency (e.g. DF growth rate) is proportional to the energy input. However, in a series of cases, an intentional introduced auxiliary activation into the diamond CVD system produced much more effect then a simple superposition of activation actions. At supplementary energy contribution of $0.01-10 \%$ in relation to the basic one, the growth rate can increase 1.2-6 times [32-34]. The DF quality in a series of cases is not worsened (Fig. 5).

Depending on the character and the directionality of action on the system 'crystallization medium - crystal', two opportunities can be surveyed: action on a gas phase (homogeneous) and on a surface of a growing crystal (heterogeneous chemical reactions).

One may speculate about how the extra activation influence the basic processes of the diamond CVD. It should be mentioned the following, probably not an exhaustive list, of specific response of the CVD system to additional activation:

- participation in formation of solid carbon in some extra concentrations of both $\mathrm{CH}_{3}$ radicals [35-37] and 
excited molecules of acetylene $[35,38]$ and other hydrocarbon molecules and particles, having high reactivity;

- participation of adsorbed hydrogen atoms during formation of diamond nuclei (the adsorption of molecules of acetylene can be carried out on two next centers, one of which is free, and another is engaged in atom of hydrogen [39-41]);

- an irradiation of a surface by electrons and quanta, that results to charging of adsorbed molecules [42, 43], to enhancement of a surface diffusion $[44,45]$ and/or hydrogen desorption rate [33].

All above factors may influence nucleation and growth rate of diamond and its quality. However character and measure of the influence, is unconditional, depend on the level of additional activation, nature and concentration of carbon precursors, substrate temperature and other parameters of the process.

Another important point - deposition of solid phases (diamond and not diamond carbon) and their gasification in diamond CVD's, proceed on different routes. That is why simultaneous use of several energy modes allows to influence almost independent as DF growth rate, and on selectivity of the process. Thus, of interest is the intentional combination of various activations aimed to clarification of the crystallization mechanism, gain in productivity of process and quality of diamond material. Thus, the hybrid methods of chemical crystallization of diamond from activated gas phase provide challenging reserve for the diamond CVD efficiency raising, and also for defect structure and impurity composition control of DF.
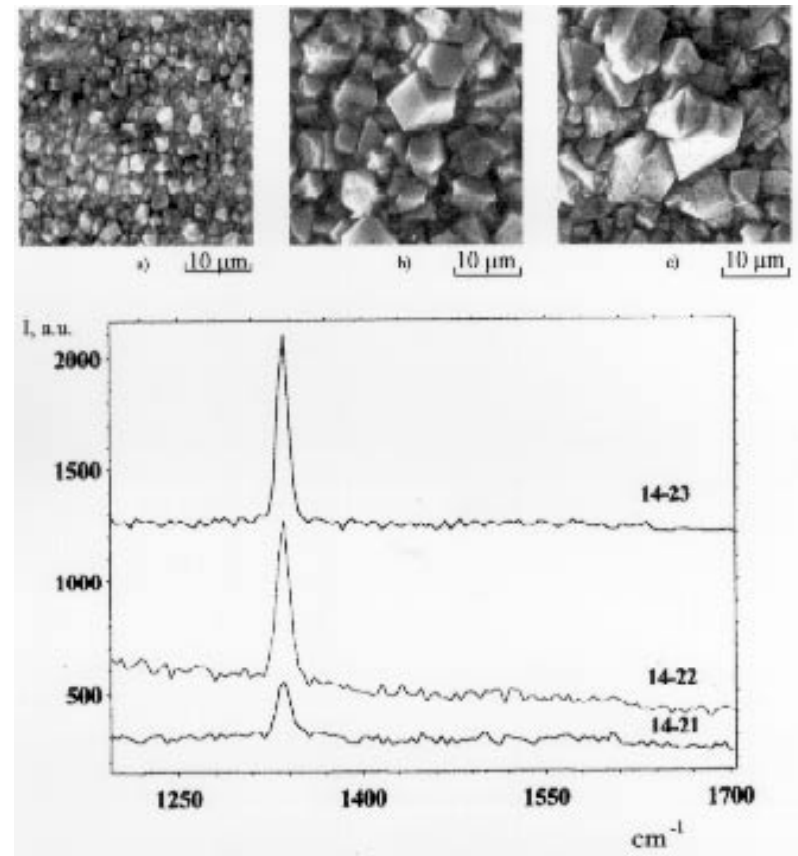

Figure 5. SEM image of the morphology of DF's \#\# 1421, 14-22, and 14-23 grown by HF technique at biases: a) $0 \mathrm{~V}$ (\# 14-21); b) +70 V (\# 14-22), c) +85 V (\# 14-23). Bottom: Raman spectra of the DF samples.

\section{Doping of diamond films}

Doping of diamond, as well as any other crystal, is meant as the formation in it of an atomically dispersive (true) solid solution, in which the impurity atoms occupy substitution or interstitial positions of crystalline lattice. Diamond doping occurs or enforced unintentionally or intentionally. In the latter case, experimentalists pursue directional change of mechanical, physical, or chemical properties of diamond. Owing to rather low diffusivity value of the majority of impurities in diamond, the solid solution can be maintained in wide temperature range. Therefore, the stability of optical, electrical and other properties of doped diamond have provided.

The number of impurities capable to replace a carbon atom in a lattice of diamond is rather restricted, owing to small covalent radius of carbon atom in diamond crystalline lattice and very high bond energies between atoms [46]. However, the adaptation of impurities as a true solid solution (equilibrium or nonequilibrium) is a necessary, but not enough condition for conversion of dielectric diamond into a doped semiconductor material with a high level of conductance. For providing of low activation energy of impurity relevant conductivity the position of additional energy level in forbidden band-gap should defend not too far, no more than approximately $0.5 \mathrm{eV}$, from the top of valence band (hole semiconductor) and, accordingly, from bottom of conduction band (electron semiconductor).

Apparently, CVD methods of crystallization of diamond provide more favorable opportunities for doping diamond than high pressure - high temperature method. Actually close to room temperature (temperature on an inlet in CVD reactor) practically any chemical element can be found in form of chemical compound, or even in the pure state [47]. It looks like by activated CVD some extra opportunities both for equilibrium and, probably, nonequilibrium DF doping in the course of their growth might be appeared. Anyway, doping DF by hydrogen $[48,49]$, and by boron, phosphorus and sulfur [50] was achieved in a chemical transport reaction mode, doping by hydrogen in the hot-filament reactor $[51,52]$, by phosphorus in isothermal diamond CVD [53] and in mW-discharge [54], and also by sulfur - in the MWACVD [55].

Hydrogen is customary constituent of vapor phase in many methods of activated CVD of diamond. That is why it is frequently a background impurity in the doped DF. The hydrogen is considered as a neutral impurity in diamond. However, it can interact with other impurity atoms, thus changing their efficiency as electrically active impurity [56]. According to ref. 52 hydrogen in polycrystalline DF can enter in concentrations from 0.02 up to 0.2 at.\%, with reduction of crystallization temperature from 850 up to $650{ }^{\circ} \mathrm{C}$. 
Now there are many publications [57] on epitaxial DF doping by boron, with obtaining of semiconductor film with p-type conductivity. The hole mobility reaches $1590 \mathrm{~cm}^{2} /$ V.s [58], that is close to hole's mobility in natural semiconductor diamond of the IIb type.

The n-type diamond semiconductor is not found in Nature. The attempts of its high-pressure synthesis and also using the method of ion implantation have not concluded by essential success. Only in our publication [50], were quoted the first positive results on the synthesis of conductive DF, doped by phosphorus and sulfur. Later persistent and consistent Japanese researchers confirmed a reality of regrowth of epitaxial DF, doped by phosphorus $[53,54]$ and by sulfur [55]. It is worth to note that according to the Rutherford backscattering technique up to $90 \%$ of phosphorus atoms replace carbon atoms in a diamond lattice [59]. It supports our preview [47], that phosphorus can be accepted by diamond lattice. We based our conclusion on the prototype molecule approach. In fact, the covalent radius of four-coordinated phosphorus in phosporus-contained molecules (tetraalkylphosphonium halogenide) has lower value than in three-coordinated phosporuscontained molecules (trialkylphosphyne). The effect may be much more pronounced in the weak phosphorusin-the diamond solid solution. The reason could be one of importance for low stress phosphorus adaptation in the state of a dilute solid solution in diamond structure [47].

Recent publications confirms the formation of ntype epitaxial DF, doped in course of growth by phosphorus. The sign of a charge of carriers, particularly by the Hall method, specifies the formation of the diamond semiconductor with an electronic type of conductivity. The Hall mobility of carriers contained from 23 to about $1000 \mathrm{~cm}^{2} /$ V.s $[53,54,60]$.

\section{DF properties}

The mechanical characteristics of the vapor-deposited diamond (elastic modulus, hardness) are close to the properties of natural diamond. On other properties, such, as resistance to brittle failure, the polycrystalline plate of diamond obtained by the CVD method can surpass the performance of natural diamond.

The experience on the diamond doping (Section VII), have shown that customarily highly dielectric diamond $\left(10^{12}-10^{14}\right.$ Ohm.cm) can, through the introduction of small amount of $(<1$ at.\%) boron and phosphorus dopant, to be transformed in a semiconductor with RT resistivity of $2.10^{-3}$ and $30 \mathrm{hm} . \mathrm{cm}$, respectively.

Combinations of the CVD and high-pressure methods provide the synthesis of monoisotopic diamondC-12 (99.98 \% of the C-12 isotope). This crystal essentially exceed the thermal conductivity level of pure nitrogen-free IIa natural diamond [61], with C-12:C-13
$=98.8: 1.2$. , by 1.5 times at $300 \mathrm{~K}$.

The optical transparence of highly perfect epitaxial DF near fundamental absorption edge (about $220 \mathrm{~nm}$ ) can exceed this quantity for the IIa diamond.

In which concerns the resistance against oxidizing by melted potassium nitrate, the boron doped epitaxial DF surpasses by approximately 6 times (111) natural diamonds, on which it was regrown [46].

Thus, mainly on the basis of new CVD's diamond we are able to state that the properties of genuine diamond are realistic not only to be reproduced, but excel seriously.

At this point, of importance will be to highlight that reviewed diamond CVDs and vapor-grown diamond are preferably not competitors to other diamond synthesis methods and diamond sources. They look rather complementary methods and resources for the Diamond Materials Science. The potential of this fascinating area in basic terms will be demonstrated in the following Sections.

\section{Heteroepitaxy of wide band-gap semiconductor on diamond}

Some expectable new results in benefits of solid state electronics, optoelectronics and lasers can be achieved by joining diamond with other wide band-gap semiconductors ( $\mathrm{SiC}, \mathrm{AlN}, \mathrm{GaN}$, and $\mathrm{BN}$ ). One of the examples of this combination is surface acoustic waves devices in two-layer system: CVD diamond - polycrystalline AIN [62]. The active acoustoelectronic structure was created by combination of dc-discharge and RF magnetron sputtering for DF and AlN film, respectively.

Other steps in hybrid structures may promote the demonstrated recently [63] heteroepitaxial AlN film deposition on nearly (111) face of natural diamond. The process take place by monoprecursor substance, $\mathrm{NH}_{4} \mathrm{AlBr}_{4}$, thermal decomposition in the ultra-pure $\mathrm{Ar}$ flow at $\sim 900^{\circ} \mathrm{C}$.

\section{Application of the CVD diamond methods and the va- por grown diamond}

In many cases the electrodeless diamoned CVD's are preferable, because the pollution of DF by impurities of metals is prevented. However, even in electrodeless methods plasma volume neighbor with walls or windows made from a quartz glass. That can result in the DF pollution by $\mathrm{Si}$ and $\mathrm{O}$ impurities. The $\mathrm{O}$ and $\mathrm{N}$ impurities (from precursor and carrier gas) in the DF are also typical. As non-impurity defect usually serves 
nondiamond carbon. It content may be minimized only at the expenses of the growth rate.

Discovered and developed originally in Russia, now diamond CVD's looks like most flexible synthesis methods. Being an alternative to the appreciated highpressure diamond synthesis, the CVD processes open new facets of the diamond as ultimate crystal for science and technology evolution. Moreover, diamond CVD is rather not competitor to other diamond sources, but rather the technology, providing much easy opportunity to integer different diamond sources (Section I), with real promise to synthesize about any diamond and diamond-based composite material in soft conditions of diamonds thermodynamic metastability.

Thermal activation of a gas phase (hot filament method), direct current arc-jet and microwave enhanced diamond CVD are most suitable for commercial use in DF, diamond foil and diamond plates production. These products find successful application as wear-resistant coatings for instruments, friction pairs, windows for $\mathrm{UV}$, visible, IR, $\mathrm{mW}$, and $\mathrm{X}$-ray radiation, thermal spreaders and heat-sinks, tensoresistive and termoresistive sensors, UV- and X-ray detectors, etc.

\section{Near future challenges and prospects}

The basic problems in the field of new CVD methods of diamond synthesis and in new diamond materials are at different stages of their development and solution. In the final we have to note the most essential issues of $\mathrm{R}$ \& D in science and technology of vapor-grown diamond:

- study of the mechanism of the diamond CVD,

- quantitative examination of hybrid methods of activated CVD of diamond,

- an examination of effective DF doping in course of its growth,

- large area regrowth of heteroepitaxial DF on cheap single crystals of nondiamond nature, and

- combination of diamond and other wide band-gap semiconductor materials ( $\mathrm{SiC}, \mathrm{AlN}, \mathrm{GaN}$, etc.) in twoand multi-film structures for benefits of high-frequency and high-power electronics, optoelectronics, lasers, and so on.

\section{General conclusion}

The diamond CVD and related areas is a rather young field of $\mathrm{R} \& \mathrm{D}$, and is still curious, attractive, and prospective for scientists and engineers. It provides us by many new effective applications, and promises us by many hidden discoveries. It looks obvious, that next and, probably, no less impressive achievements in the area will be feasible mainly with interdisciplinary approaches and with international cooperation in outlined fascinated area of physics, chemistry and technologies.

\section{Acknowledgments}

The authors highly appreciated A.A. Botev for participation in experiments. We wish to express gratitude to A.D. Aliev for SEM micrographs, and N.N. Mel'nik and T.N. Zavaritskaya - for the Raman study of the diamond films. We also are thankful to N.A. Abatourova and I.V. Galoushko for assistance in preparing of the manuscript. We highly acknowledge partial support of research from grants Sandia National Laboratories (USA) AN-8800, Argonne National Laboratory (USA) 951932404, and RBRF (Russia) 98-03-32601.

\section{References}

[1] J.T. Field, Ed., Properties of Natural and Synthetic Diamond, Acad. Press, London, 1992.

[2] B.V. Spitsyn, L.L. Bouilov, and B.V. Deryaguin, J. Cryst. Growth 52, 219 (1981).

[3] J.J. Lander and J. Morrison, Surface Science 4, 241 (1966).

[4] B.V. Spitsyn and B.V. Deryaguin, USSR Author's Certificate No 339134, Appl. 964957/716358, filed July 10, 1956.

[5] W.G. Eversole, US Patent No 3030187, filed July 23, 1958.

[6] W.G. Eversole, US Patent No 3030188, filed July 23, 1958

[7] B.V. Deryaguin and D.V. Fedoseev, Uspekhi Khimii 39, 1661 (1970).

[8] B.V. Spitsyn, Ph.D. Thesis, Inst. Phys. Chem. RAS, Moscow, 1966.

[9] B.V. Deryagin, B.V. Spitsyn, D.V. Fedoseev, V.A. Ryabov, A.V. Bochko, and A.V. Lavrent'ev, Fiz.Khim. Probl. Kristalliz. 1971, 2, 90 (in Russian).

[10] B.V. Deryaguin, D.V. Fedoseev, V.N. Bakul', V.A. Ryabov, B.V. Spitsyn, Yu. I. Nikitin, A.V. Bochko, V.P. Varnin, A.V. Lavrent'ev, and V.L. Primachuk. Physical-Chemical Synthesis of Diamond from Vapor Phase, Tekhnika, Kiev, 1971.

[11] B.V. Spitsyn, Dr. Sci. Thesis, Inst. Phys. Chem. RAS, Moscow, 1973.

[12] B.V. Spitsyn, The roads to metastable diamond growth, Diamond Materials, ed. J. P. Dismukes and K. V. Ravi, Electrochemical Society Proc., v.93-17, 1993, 345 .

[13] E.A. Gulbransen, et.al., J. Electrochem. Soc. 112, 44 (1965).

[14] A.V. Botev, Master Thesis, Moscow, 1978.

[15] B.V. Spitsyn, Growth of diamond films from the vapour phase, Handbook of Crystal Growth. Vol. 3A, D.T.J.Hurle, Ed., Elsevier, 1994, Ch.10, 401. 
[16] Handbook of Industrial Diamond and Diamond Films. M.A. Prelas et al., eds., Marcel Dekker, N. Y., 1998, $1224 \mathrm{pp}$.

[17] In ref. 15, p.415.

[18] A.E. Alexenko and B.V. Spitsyn, Diam. Relat. Mater. 1, 705 (1992)

[19] K. Suzuki, A. Sawabe, H. Yasuda, and T.Inuzuka, Appl. Phys. Lett. 50, 728 (1985).

[20] K. Suzuki, A. Sawabe, and T.Inuzuka, Jpn J. Appl. Phys. 29, 153 (1990).

[21] K. Kurihara, K. Sasaki, M. Kawarada, and N. Koshino, Appl. Phys. Lett. 52, 437 (1988).

[22] M.A. Cappelli, in: Handbook of Industrial Diamond and Diamond Films. M.A. Prelas et al., eds., Marcel Dekker, N. Y., 1998, 865.

[23] R. Mania, L. Stobierski, and P. Pampuch, Cryst. Res. Technol. 16, 785 (1981).

[24] S. Mitura, A. Mitura, P. Niedzielski, and P. Couvrat, Chaos, Solitons \& Fractals 10, 2165 (1999).

[25] S. Matsumoto, M. Hino, and T. Kobayashi, Appl. Phys. Lett. 51, 737 (1987).

[26] M. Kohzaki, K. Higuchi, S. Noda, and K. Uchia, Diam. Relat. Mater. 2, 612 (1993).

[27] M. Kamo, Y. Sato, S. Matsumoto, and N. Setaka, J. Cryst. Growth 62, 642 (1983)

[28] P.K. Bachmann, in: Handbook of Industrial Diamond and Diamond Films, M.A. Prelas et al., eds., Marcel Dekker, N. Y., 1998, 821.

[29] J. Wei, H. Kawarada, J. Suzuki, and A. Hiraki, J. Cryst. Growth 99, 1201 (1990).

[30] P.W. Morrison Jr. and J.T. Glass, in: Properties and Growth of Diamond, G. Davies, Ed., EMIS Datareviews, Series No 9 , Short Run Press Ltd., Exeter (1994), 392.

[31] B.V. Spitsyn, A.E. Alexenko, and L.L. Bouilov, Diam. Relat. Mater 8, 1371 (1999).

[32] A. Sawabe and T. Inuzuka, Appl. Phys. Lett. 46, 146 (1985).

[33] M. Kamo, T. Ando Y. Sato, K. Bando,and J. Ishikawa, Diam. Relat. Mater. 1, 104 (1992).

[34] S.K. Baldwin, T.G. Owano, M. Zhao, and Ch.H Kruger, Diam. Relat. Mater., 6, 202 (1997).

[35] M. Tsuda, et al., J. Am.Chem. Soc. 108, 5780 (1986).

[36] M. Frenklach and K.E. Spear, J. Mater. Res. 3, 133 (1988).

[37] S.J. Harris, J. Appl. Phys. 65, 3044 (1989).

[38] A.E. Alexenko, Ph.D. Thesis, Inst. Phys. Chem. RAS, Moscow, 1989.

[39] B.V. Derjaguin, B.V. Spitsyn, L.L. Bouilov, A.E. Alexenko, and A.A. Botev, in: Superhard Materials: Synthesis, Properties, Applications, N.V. Novikov, Ed., Kiev (1983), 50 (in Russian).

[40] L.L. Bouilov, Ph.D.Thesis, Inst. Phys. Chem. RAS, Moscow, 1988.
[41] L.L. Bouilov, 2-nd Int. Symp. on Diamond Films / NATO Advanced Workshop on Wide Bandgap Electronic Materials (Minsk, 1994), Abstr. Booklet, 160 (1994).

[42] K.I. Chopra, J. Appl. Phys. 37(6), 249 (1966).

[43] V.B. Kazansky and N.D. Tshuvylkin, Dokl. Akad SSSR 223(4), 910 (1975).

[44] M. Frenklach and S.Sokov, J. Phys. Chem. B 101, 3025 (1997).

[45] K.Larsson, Proc. 5-th Appl. Diam. Conf. / 1st Frontier Carbon Technol.Conf., Tsukuba, Japan, (1999) 42.

[46] B.V. Spitsyn and A.E. Alexenko, Archivum Nauki o Materialakh 6, 201 (1986).

[47] B.V. Spitsyn, A.V. Dobrynin, A.F. Belyanin, I.V. Galouchko, A.B. Spitsyn, A.E. Alexenko, L.L. Bouilov, and V.P. Stoyan, Proc. 5-th Int. Symp. on Diamond Materials, Ed. by J.L.Davidson, W.D. Brown, A. Gicquel, B.V. Spitsyn, and J.C. Angus. Vol. 97-32, 70 (1998).

[48] L.D. Kislovskii and B.V. Spitsyn, Soviet Physics Crystallography 25, 239 (1980)

[49] L.G. Karaseva, T.A. Karpukhina, and B.V. Spitsyn, Sovjet Physical Chemistry, 1983, 302.

[50] B.V. Spitsyn, Proc. of the NIRIM Int. Symp. on Advanced Materials '94, Tsukuba, Japan, March 13-17, 1994. Ed. by M. Kamo, H. Kanda, Y. Matsui, and T. Sekine, NIRIM, 1994, 169.

[51] S. Khasawinah, T. Sung, B. Spitsyn, W. H. Miller, G. Popovici, M.A. Prelas, E.J. Charlson, E.M. Charlson, J. Meese, and T. Stacy, in: Diamond Materials, ed. J.P. Dismukes and K.V. Ravi, Electrochemical Society Proc. v.93-17, 1032 (1993).

[52] A.B. Spitsyn, I.V. Galoushko, and A.F. Belyanin, in: Proc. 4-th Int. Symposium on Diamond Films and Related Materials, Kharkov, Ukraine, 20 - 25 September, 1999, ed. by A.F. Belyanin, M.A. Prelas, V.M. Shulaev, and B.V. Spitsyn, Kharkov, 1999, 23.

[53] T. Nishimori, et al., Appl. Phys. Lett. 71, 945 (1997).

[54] S. Koizumi, et al., Appl. Phys. Lett. 71, 1095 (1997).

[55] I. Sakaguchi, M.N.-Gamo, Y. Kikuchi, E. Yasu, H. Haneda, T. Suzuki, and T. Ando, Phys. Rev., B 60, R2139 (1999).

[56] J. Chevallier, B. Theys, A. Lusson, C. Grattepain, A. Deneuville, and E. Gheeraert, Phys. Rev. B 58, 7966 (1998).

[57] K. Okano, in Diamond: Electronic Properties and Applications, L.S. Pan and D.R. Kania, eds., Kluwer Academic Publishers, Dordrecht, 1995, 139.

[58] B.A. Fox, M.I. Hartsell, D.M. Malta, H.A. Wynands, C.-T. Cao, L.S. Plano, G.J. Tessmer, R.B. Henard, J.S. Holmes, A.J. Tessmer, and D.L. Dreifus, Diam. Rel. Mater. 4, 622 (1995).

[59] Mikka N.-Gamo, personal communication, October, 1999.

[60] T. Nishimori, 6-th Int. Symp. on Diam. Mater. (Honolulu, Oct. 17-22, 1999), Ext. Abstr No 803. 
[61] T.R. Anthony, W.R. Banholzer, J.F. Fleischer, L. Wei, P.K. Kuo, R.L. Thomas, and R.W. Prior, Phys. Rev. B 42, 1104 (1990).

[62] A.F. Belyanin, L.L. Bouilov, V.V. Zhirnov, A.I. Kamenev, K.A. Koval'sky, and B.V. Spitsyn, Diam.
Rel. Mater. 8, 369 (1999).

[63] A.E. Gorodetsky, R.Kh. Zalavutdinov, A.P. Zakharov, W.L. Hsu, B.V. Spitsyn, L.L. Bouilov, and V.P. Stoyan, Diam. Rel. Mater. 8, 1267 (1999). 